\title{
An Unusual Cause of Low Back Pain: Uterine Conditions
}

\author{
Yunus Durmaz ${ }^{1}$, Ilker Ilhanli ${ }^{2,}$, Kivanc Cengiz $^{3}$, Murat Gul ${ }^{4}$ \\ ${ }^{1}$ Department of Physical Medicine and Rehabilitation, Division of Rheumatology, Mehmet Akif Inan Training and Research Hospital, \\ Sanliurfa, Turkey \\ ${ }^{2}$ Department of Physical Medicine and Rehabilitation, School of Medicine, University of Giresun, Giresun, Turkey \\ ${ }^{3}$ Department of Physical Medicine and Rehabilitation, Division of Rheumatology, Sivas Numune Hospital, Sivas, Turkey \\ ${ }^{4}$ Department of Statistics, Faculty of Science, University of Giresun, Giresun, Turkey
}

\section{Email address:}

ilkerilhanli@hotmail.com (I. Ilhanli)

\section{To cite this article:}

Yunus Durmaz, Ilker Ilhanli, Kivanc Cengiz, Murat Gul. An Unusual Cause of Low Back Pain: Uterine Conditions. American Journal of Clinical and Experimental Medicine. Vol. 3, No. 6, 2015, pp. 335-337. doi: 10.11648/j.ajcem.20150306.13

\begin{abstract}
The etiology of low back pain is often thought to include musculoskeletal disorders, such as lomber disc herniation or strain.Less commonly, low back pain is thought to refer from viscera.Sources of pain referred to the low back in females include uterine conditions. We aimed to investigate the female population of a rheumatology clinic to define the rate of uterine conditions that a rheumatologist can meet, and explore the possible association between uterine conditions and low back pain. Clinical data and imaging findings of 320 female patients who admitted to rheumatology clinic with the complaint of low back painwere retrospectively reviewed. Uterine myoma was detected in 20 patients $(6,25 \%)$, and uterus retroversion was detected in only 3 patients $(0,93 \%)$. Any reason of low back pain, except uterine myoma could be found in 4 of 20 patients.Patients did not meet the criterias for any of the inflammatory or mechanical causes of low back pain including fibromyalgia syndrome, and their sedimentation and CRP rates were normal, too.Low back pain which was explained by uterine anomaly rate was 2,18\%.All 7 patients with uterine anomaly were complaining of low back pain with mechanical characteristics. Uterine myoma and uterus retroversion should be kept in mind by the physicians who meet with female patients at premenopausal ages suffering from low back pain after excluding the common causes of this condition.
\end{abstract}

Keywords: Uterine Myoma, Uterus Retroversion, Low Back Pain

\section{Introduction}

Prevalence of low back pain (LBP) is high in urban societies, and there is a high demand for medical care.Because of being a common cause of disability and work loss, LBP is emerging as a common socioeconomic and sociomedical problem. Approximately, $60-80 \%$ of the adults suffer from LBP during their life. Despite the high frequency of LBP, incidence of lomber disc herniation (LDH) is less than the expected, and it is nearly $1-3 \%$ of the general population [1]. The etiology of LBP is often thought to include musculoskeletal disorders, such as LDH or strain [2].

Less commonly, LBP is thought to refer from viscera, such as from kidney, [3, 4] aorta, [5] or metastasis [6, 7]. Other sources of pain referred to the low back in females include uterine conditions [8-13]. But these conditions are unusual and very difficult to discriminate from other common causes of LBP. In this study, we aimed to investigate the female population of a rheumatology clinic to define the rate of uterine conditions that a rheumatologist can meet, and explore the possible association between uterine conditions and LBP.

\section{Materials and Methods}

Clinical data and imaging findings of female patients who admitted to rheumatology clinic with the complaint of LBP from january 1to october 31, 2015 were retrospectively reviewed. Exclusion criterias forthe study were age $<18$ years, patients without sacroiliac joint magnetic resonance imaging (MRI), patients without lomber MRI, and patients without written consents to use their data. Three hundred and twenty patients who meet the criterias were included in the study. Age, diagnosis, duration of complaint, and type of the LBP (mechanical or inflammatory) were recorded. All sacroiliac MRI results, and lomber MRI results were investigated, and detected pathologies were recorded. All images were examined for possible uterine anomalies. Patients who didn't have other possible causes for LBP, except uterine anomalies were discriminated.

In this study, data analysis was made using the SPSS 21 software package. Frequencies of the variables were calculated. Due to not providing assumption of normality, to compare the variables Kruskal-Wallis testwas used. $\mathrm{P}<0,05$ 
was considered statistically significant.

\section{Results}

Three hundred and twenty female patients' data were included in the study. Mean age was $37 \pm 11,4$ years. Mean of the duration of complaints was $18,01 \pm 17,04$ months.

Uterine myoma was detected in 20 patients $(6,25 \%)$, and uterus retroversion was detected in only 3 patients $(0,93 \%)$. We couldn't find another type of uterus anomaly in MRI. There wasn't another defined gynecologic diagnosis of patients.

Any reason of LBP, except uterine myoma could be found in 4 of 20 patients $(1,25 \%$ of all patients, and $20 \%$ of patients with uterine myoma). MRI did not show any evidence of spinal canal stenosis or nerve root impingement in these patients. Patients did not meet the criterias for any of the inflammatory or mechanical causes of LBP including fibromyalgia syndrome, and their sedimentation and CRP rates were normal, too. We couldn't establish an association between LBP and uterine myoma in 16 patients, because we explainedLBP with other possible causes. Also we couldn't find any possible reason of LBP, except uterus retroversion in 3 patients. All of these 3 patients were suffering from dysmenorrhea, one of them was suffering from premenstrual pain, and the other one from dyspareunia. We found any uterus anomaly in 297 of 320 patients with LBP. Low back pain which was explained by uterine anomaly rate was $2,18 \%$ (7 of 320 patients).

Mean age of the patients with LBP associated with uterine myoma was 43,75 $\pm 4,35$ years (Median 42,5 years), where the mean age of the patients with LBP associated with uterus retroversion was 34,33 $\pm 17,39$ years (Median 34 years). However, mean age of the patients with LBP which wasn't

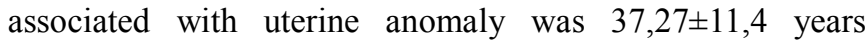
(Median 37 years). There was no difference among these groups according to mean age ( $p>0,05$, Table 1). Also, there was no difference among these groups according to duration of complaints ( $p>0,05$, Table 1$)$.

Table 1. Mean of the age, and mean of the duration of complaints of the patients with LBP associated or not associated with uterine conditions.

\begin{tabular}{lllll}
\hline & MU $(\mathbf{N}=4)$ & UR $(\mathbf{N}=3)$ & LBP $(\mathbf{N}=313)$ & P value \\
\hline $\begin{array}{l}\text { Mean age } \\
\text { (years) }\end{array}$ & $43,75 \pm 4,35$ & $34,33 \pm 17,39$ & $37,27 \pm 11,4$ & 0,364 \\
$\begin{array}{l}\text { Duration of } \\
\text { complaints } \\
\text { (months) }\end{array}$ & $13,25 \pm 7,89$ & $16 \pm 6,93$ & $18,09 \pm 17,19$ & 0,839 \\
\hline
\end{tabular}

Significance level: $\mathrm{p}<0,05$, LBP: Low back pain, MU: Low back pain associated with myoma uteri, UR: Low back pain associated with uterus retroversion, LBP: Other possible causes of low back pain except uterine anomalies.

All 7 patients with uterine anomaly were complaining of LBP with mechanical characteristics.A hundred and ninety of 313 patients $(60,7 \%)$ with other causes of LBP were complaining of pain with mechanical characteristics, where 123 of 313 patients $(39,3 \%)$ were complaining of LBP with inflammatory characteristics. Other diagnoses of patients with LBP, except uterine anomalies, and their rates are shown in Table 2. Sacroiliac MRI results of 7 patients with uterine anomalies were normal. Other 313 patients' MRI results of sacroiliac joints are shown in Table 3.

Table 2. Other diagnoses of patients with low back pain, except uterine conditions.

\begin{tabular}{llllll}
\hline & N & Percent & & N & Percent \\
\hline AS & 57 & 17,8 & AS+HNP & 1 & 0,3 \\
SpA & 35 & 10,9 & FacD & 2 & 0,6 \\
Bruc & 4 & 1,2 & PMR & 1 & 0,3 \\
FMS & 82 & 25,3 & Sacra & 1 & 0,3 \\
Spon & 14 & 4,4 & Other & 106 & 35,8 \\
HNP & 10 & 3,1 & & & \\
\hline
\end{tabular}

AS: Ankylosing spondylitis, SpA: Spondyloarthropathy, Bruc: Brucellosis, FMS: Fibromyalgia syndrome, Spon: Spondylosis, HNP: Hernia nucleus pulposus, FacD: Facet dysfunction, PMR: Polimyalgia rheumatica, Sacra: Sacralization, Other: Other inflammatory or mechanical disorders like psoriatic arthritis, inflammatory bowel diseases, Tarlow's cyst, sacral arachnoidal cyst etc.

Table 3. Magnetic Resonance Imaging results of sacroiliac joints of 313 patients with low back pain.

\begin{tabular}{lll}
\hline & N & Percent \\
\hline Bilateral active sacroilitis & 52 & 16,6 \\
Chronic sacroilitis & 25 & 8 \\
Unilateral sacroilitis & 24 & 7,7 \\
Active-chronic sacroilitis & 2 & 0,6 \\
Normal & 210 & 67,1 \\
\hline
\end{tabular}

\section{Discussion}

Uterine myoma is a common condition ( 1 of 5 ) for the females in reproductive ages [14]. Abnormal uterine bleeding, pain, compression signs like urine retention or constipation, infertility and loss of pregnancy are the most seen symptomes of uterine myoma [15]. Uterine anomalies like leiomyoma,[8] uterus didelphys, [9] uterine fibroid, [10] hematometra [11] are unusual causes of LBP,and it is difficult to connect them with LBP instead of the other common causes of LBP. In our study, rate of uterine myoma was found $6,25 \%$, which was lower than the literature and the symptomatic uterine myoma (which was thought to be associated with LBP) rate was $1,25 \%$. In patients with myoma we couldn't find the data of dysmenorrhea, premenstrual pain, dyspareunia or bladder and bowel symptoms. Because of the intensity of gynecologic symptomes, patients may appeal to gynecology clinics rather than rheumatology clinics, and this may be the cause of the lower rates.

Among healthy women, 1 in 5 have a uterus retroversion either as a normal variant of uterine position or as an acquired condition. Retrovertion can be associated with LBP, as well as the chronic pelvic pain. Also it can cause congestive dysmenorrhea, deep dyspareunia, and bladder and bowel symptoms [16, 17]. There are surgical interventions for the treatment of the symptomatic uterus retroversion, and it is important to diagnose and treat this abnormality. In our study, uterus retroversion was detected in $0,93 \%$ of patients which was contrast to the literature [16, 17]. Existing dysmenorrhea, premenstrual pain and dyspareunia in our patients intensified our diagnosis of symptomatic uterus retroversion. 
Referred pain is the pain that is felt in a part of the body at a distance from its area of origin [18]. It has been described as nonspecific, deep, diffuse, and dull [19]. The exact mechanism is not yet known, although a number of neuroanatomic and physiologic theories have been suggested $[2,18,20]$. Furthermore, referred pain differs from radicular pain, which is pain originating from a nerve root [21]. According to our knowledge, sympathetic fibers deriving from the superior hypogastric plexus, and the parasympathetic fibers from S2, S3, and S4- which are related with the uterosacral ligaments- are associated with the menstrual pain [16]. Probably, the same mechanism causes the LBP. As we stated before LBP of our patients with uterine conditions had mechanical characteristics. Also, lomber and sacroiliac MRI results were normal. There was no radiculopathy sign or muscle spasm in all 7 patients, and they didn't meet the criterias of fibromyalgia syndrome. We found any abnormality in the physical examination of these patients. So we couldn't define the cause of LBP with a common cause of LBP and thought that it was a reffered pain emerged from uterine condition.

We thought that it is important to discriminate the characteristics of LBP whether it is mechanical or inflammatory. Furthermore, all other common causes of LBP should be excluded with detailed physical examination, and laboratory and radiological investigation.Indisputably, every kind of diagnostic method should be used to reduce our doubts about the diagnosis. All these patients were referred to gynecology clinic. We couldn't follow these patients' investigation and treatment process at gynecology clinic. This is thelimitation of our study, because we have to know the response of LBP to the gynecological treatment to confirm the referred pain due to uterine conditions.Despite being a rare clinical entity, further studies should be conducted with large subject numbers and patients should be followed by both rheumatology and gynecology clinics.

\section{Conclusion}

Uterine myoma and uterus retroversion should be kept in mind by the physicians who meet with female patients at premenopausal ages suffering from LBP after excluding the common causesof LBP.

\section{References}

[1] Andersson GB. Epidemiological features of chronic low-back pain. Lancet 1999; 354: 581-585.

[2] Gatterman MI. Chiropractic management of spine related disorders. Philadephia: Williams \& Wilkins; 1990.

[3] Collins RD. Algorithmic diagnosis of symptoms and signs. Philadelphia: Lippincott Williams \& Wilkins; 2003.

[4] Watkins CT, Tao C, Yochum TR. Renal cell carcinoma in a 44-year-old man: an etiology for low back pain. J Manipulative Physiol Ther 2009; 32(7):597-600.

[5] Fielding JWL, Black J, Ashton F. Diagnosis and management of 528 abdominal aortic aneurysms. BMJ 1981; 283(6287):355-9.

[6] Baxi SC. Low back pain resulting from Paget disease of bone in a patient with known prostate cancer: case report and review of the literature. Endocrinologist 2005; 15(6):384-90.

[7] Johnson Jr TL. Abdominal and back pain in a 65-year-old patient with metastatic prostate cancer. Journal of Chiropractic Medicine 2010; 9(1):11-6.

[8] Onu DO, Fiorentiono LM, Bunting MW. Cotyledonoid dissecting leiomyoma as a possiblecause of chronic lower back pain. BMJ Case Rep 2013. doi: 10.1136/bcr-2013201350 .

[9] Knight RJ, Birkinshaw R. An unusual cause of lower back pain: uterus didelphys and unilateral cervical atresia. Int J Clin Pract Suppl 2005; (147):125-7.

[10] Bodack MP, Cole JC, Nagler W. Sciatic neuropathy secondary to a uterine fibroid: a case report. Am J Phys Med Rehabil 1999; 78(2):157-9.

[11] Deathe AB. Hematometra as a cause of lumbar radiculopathy. A case report. Spine (Phila Pa 1976) 1993; 18(13):1920-1.

[12] Al-Jefout M, Dezarnaulds G, Cooper M, Tokushige N, Luscombe GM, Markham R, et al. Diagnosis of endometriosis by detection of nerve fibres in an endometrial biopsy: a double blind study. Hum Reprod 2009; 24(12):3019-24.

[13] Yeniel O, Cirpan T, Ulukus M, Ozbal A, Gundem G, Ozsener $\mathrm{S}$, et al. Adenomyosis: prevalence, risk factors, symptoms and clinical findings. Clin Exp Obstet Gynecol 2007; 34(3): 163-7.

[14] Stones RW. Myomas. In: Stones RW(ed). Expert reviews on current research. Health Press: 2003: 42-50.

[15] ButtramVC, Reiter RC. Uterin leiomyomata: etiology, symtomatology and management. Fertil Steril 1981; 36: 43345 .

[16] Porpora MG, Gomel V. The role of laparoscopy in the management of reproductive age. Fertil Sterile 1997; 68: 76579.

[17] Fauconnier A, Dubuisson JB, Foulot H, Deyrolles C, Sarrot F, Laveyssière MN, Jansé-Marec J, Bréart G.Mobile uterine retroversion is associated with dyspareunia and dysmenorrhea in an unselected population of women. Eur J Obstet Gynecol Reprod Biol 2006; 127(2): 252-6.

[18] Jensen AM, Bewketu B, Sanford D. Intermittent low back pain referred from a uterine adenomyosis: a case report. Journal of Chiropractic Medicine 2011; 10: 64-9.

[19] Arendt-Nielsen L, Svensson P. Referred muscle pain: basic and clinical findings. Clin J Pain 2001; 17(1): 11-9.

[20] Cervero F, Laird JMA. Visceral pain. Lancet 1999; 353(9170): 2145-8.

[21] Bogduk N. On the definitions and physiology of back pain, referred pain, and radicular pain. Pain 2009; 147(1-3): 17-9. 